\title{
China in Action - Starry Sky Project of China
}

\author{
Xiaohua Wang, Yifeng Wang and Hui Ren \\ Room 501 Rongsheng Tower, No.5 Financial Street, Xicheng District, Beijing, China, 100032 \\ email: mr_wxh@hotmail.com
}

Abstract. Two pilot Starlight Parks and Protection Areas are under planning.

Keywords. Light Pollution, Starlight Park

Starry Sky Protection is an inevitable subject in the human pursuit of high-quality environment. China also needs a clear night sky. Light pollution first threatens astronomical observation, but to control light pollution needs the action of the whole society. Starry Sky Protection is a long-term task and needs a sustainable model. To combine it with tourism is an effective approach. Based on the above basic understanding, we started to initiate and promote the Project of Starry Sky in China.

We introduced the topic of light pollution in the Chinese National Geography (CNG) magazine of March 2012. There is a total of 4 articles and 50 charts covering light pollution, star observation, changes of the observatory, and dark sky park in altogether 50 pages. The CNG is one of China's most influential magazines, with a monthly circulation of one million copies. We then provided articles of starlight tourism to the Tourism World magazine of April 2012, which took up 1/3 of the magazine.

Taking reference from the programs and standards of Dark Sky Parks and Starlight Reserves, we are planning two pilot Starlight Parks \& Protection Areas at the Starlight Lake in Mt. Yimeng and the Seven Star Mesa in Mt. Tai in Shandong Province. We plan to inject ecological, scientific and cultural elements into the tourism areas and create the basis for appreciation, education and protection of the starry sky. Our work has been supported by the operators of these tourism areas and local governments. We worked out the program and prepared to establish standards and draw experience from the scenic area planning, astronomical facilities, lighting control, staff training and tourism operation. Our idea is this: the Starlight Park \& Protection Area will combine with the tourism area, natural and cultural heritage, and astronomical observatory, to create a replicable model, so that the starry sky protection can move on rapidly and gain sustainable development.

The Starry Sky Protection is a cross-industry project and requires the whole society to participate. We are pleased to have a group of people to work for it in China, including astronomy professionals, tourism and investment entrepreneurs, media and law practitioners, and young volunteers. They are from different sectors and contribute their efforts to the common cause. This cause should be recognized and protected by law. In this regard, we have also carried out research and preparation. China is a big country with unique social and cultural patterns. We are actively contacting relevant agencies, to form a joint force at a higher level, and when conditions permit, we plan to establish the Starry Sky Protection Agency of China.

In Beijing and other big cities, young people born in the 80s and 90s are already away from the splendid starry sky. How shall we face our children, and children of our children?! 